\title{
Diego de Riaño y los maestros de la Colegiata de Valladolid*
}

Begoña Alonso Ruiz

Instituto Universitario de Historia Simancas. Universidad de Valladolid

\begin{abstract}
RESUMEN. Pese al empeño del cabildo y el apoyo real dispensado a la construcción de la conocida como tercera colegiata de Valladolid, apenas existen noticias que aporten luz sobre su proceso constructivo. Gracias a la localización de nueva documentación, este trabajo indaga en la vida (y en algún caso, en la muerte) de sus tres maestros mayores: Diego de Riaño, Rodrigo Gil de Hontañón y Juan de la Cabañuela, aportando nueva información sobre la construcción del templo, así como otros trabajos de sus responsables por tierras castellanoleonesas

Palabras clave: Arquitectura, tardogótico, cantería, pleitos, Sevilla, Valladolid, León.

ABSTRACT. In spite of the zeal of the town council and the real support excused the construction of Valladolid's the most important temple, escarce documental references exist that they contribute light on the constructive process. Thanks to the localization of new documentation, this work investigates in the life of their three architects: Diego de Riaño, Rodrigo Gil de Hontañón and Juan de la Cabañuela, contributing new information on the construction of this temple, as well as other works of their sponsors for ours lands.

Key Words: Architecture, late gothic, stonecutting, lawsuits, Seville, Valladolid, León.
\end{abstract}

La conocida como "colegiata de los cinco maestros", o "colegiata de Riaño", se iniciaba con trazas elaboradas por una junta de arquitectos elegidos entre los maestros

* Este trabajo se ha realizado en el marco de la investigación "Los Talleres artísticos de las catedrales castellanas en el último periodo gótico (1430-1530)", subvencionado por la Junta de Castilla y León (ref. VA 114-04). Estoy en deuda con María José Redondo quien corrigió un primer manuscrito de este texto, orientándome sobre el entramado de las relaciones profesionales de Rodrigo Gil. Fernando Marías y Agustín Bustamante tuvieron la amabilidad de enriquecer este trabajo con sus generosas sugerencias. A don Jonás de Castro, archivero de la Catedral de Valladolid, debo su ayuda en el rastreo de las fuentes documentales catedralicias.
}

de las últimas catedrales góticas españolas: Juan y Rodrigo Gil de Hontañón, Juan de Álava, Francisco de Colonia y Diego de Riaño ${ }^{1}$. Los maestros seleccionados ${ }^{2}$ debie-

\footnotetext{
${ }^{1}$ N. ALONSO CORTÉS, "Miscelánea vallisoletana. I. La primitiva catedral", Boletín de la Real Academia de Bellas Artes de Valladolid, 15 (1936), p. 2.

${ }^{2}$ Destacan significativas ausencias como las de los maestros mayores de León (Juan de Badajoz el Mozo), Oviedo (Juan de Cerecedo), y Palencia (Gaspar de Solórzano), así como de los maestros reales Luis de Vega o Enrique Egas. Sobre los maestros que se presentaron y los elegidos véase: J. AGAPITO Y REVILLA, "Para la historia de la iglesia mayor de Valladolid", Boletín de la Sociedad Española de Excursiones, XLVI (1942), p. 225 y M. J. REDONDO CANTERA, "Los arquitectos y canteros del entorno de Rodrigo Gil de Hon-
} 
ron reunirse en Valladolid con anterioridad a abril de 1526 en que moría el viejo Hontañón, elaborando las trazas ${ }^{3}$ del nuevo templo que construiría Diego de Riaño. Era ésta la oportunidad buscada por Riaño tras su regreso a la obra de la catedral de Sevilla en 1523, avalado por su dilatada experiencia en el gran taller hispalense y su disponibilidad para la obra vallisoletana al no tener aún mayores responsabilidades en otras grandes construcciones (aunque su acumulación de cargos será inminente) ${ }^{4}$.

El sábado 25 de mayo de 1527 se comenzó a traer "la primera carretada que trae la primera piedra" de "tan grande y tan sumptuosa obra". El cabildo era consciente de la relevancia de su empeño, dejando constancia de que "...quyeren luego començar con quanta suntuosidad que ellos puedan y porque los que despues dellos subçediere tengan noti(ci)a del año questubieron en començar tan grande y sumptuosa obra y con tan pocos dineros como la fabrica tiene (entre líneas: que son myll ducados) y para que esto tomen dictado para que este edifiçio lleben adelante y se

tañón en Castilla y León: la herencia paterna", Actas del Congreso El arte de la cantería, Rodrigo Gil de Hontañón. Santander, 2003, p. 22.

${ }^{3}$ Éstas debían ser las trazas que Pedro de Olea debía entregar al canónigo Alcaráz por órden del Cabildo del 12 de abril de 1553. A.C.V. Libro Secreto del prior y cabildo desta yglesia colegial de Valladolid, desde enero 1547.

${ }^{4}$ Riaño era entonces ya un maestro reconocido aunque aún no consagrado (pese a la opinión de J. AgAPITO y REVILLA, "Para la historia...", p.225). Había iniciado su formación en el taller de la catedral de Sevilla a las órdenes de Juan Gil de Hontañón, donde se encontraba en 1517 cuando la muerte de su compañero Pedro de Rozas le obligó a exiliarse en Portugal. El 17 de septiembre de 1522 pedía el perdón real, intercediendo por él la reina doña Leonor ya que Riaño había "servido mucho tiempo al Rey mi sennor de gloriosa memoria". Consta su presencia en Sevilla en junio de 1523, siendo nombrado maestro de la fábrica hispalense el 28 de enero de 1528. (A. J. MORALES, "Diego de Riaño en Lisboa", en Archivo Español de Arte, 264 (1993), pp. 404-408). acuerden de los que comencaron y rruegen a dios por ellos..." ${ }^{5}$. A comienzos de junio se derribaban las primeras casas para allanar el solar sobre el que debía construirse el templo y el 13 de junio se colocaba la primera piedra con toda solemnidad, dentro del programa de celebraciones que vivió Valladolid con motivo del nacimiento del príncipe Felipe el día 21 de mayo ${ }^{6}$.

La nueva colegiata que sustituiría a la gótica ("muy estrecha y no de buenos edificios" ${ }^{\prime 7}$ ) debía avanzar sin tocar la antigua edificación, desde los pies por el lado de la Epístola. Como hermana de las catedrales de Salamanca y Segovia, la nueva colegiata fue diseñada con tres naves más otras dos de capillas hornacinas, como parece deducirse del trazado planimétrico de la catedral actual, heredero de la tardogóti$\mathrm{ca}^{8}$. Lo que debió de ser un esfuerzo singular, con los mejores arquitectos del momento involucrados en el proyecto, ha quedado relegado en el trabajo de los historiadores, más ocupados hasta ahora en el estudio de otro proyecto, también frustrado: la gran catedral herreriana. Una revisión de los fondos de los archivos de la catedral, de los protocolos notariales y los pleitos localizados en la Real Chancillería de Valladolid,

-

${ }^{5}$ Rodrigo Herrezuelo, arcediano de Valladolid y mayordomo de la fábrica de la iglesia colegial, testificaba entonces que en esa fecha se comenzó a traer las carretadas de piedra (pagadas a 2 reales cada una). A.H.P.Va., Sig. 7, fol.123. Recientemente publicado en M.J. REDONDO CANTERA, "La primera piedra de la posterior Catedral de Valladolid", Boletín del Seminario de Arte y Arqueología de Valladolid, LXVII (2001), pp.189 y ss.

${ }^{6}$ J. Antolínez De Burgos, Historia de Valladolid, Ed. Facsímil, Valladolid, 1987, p. 195.

${ }^{7}$ El obispo Acevedo en 1601 se refería así a la colegiata. Cit. V. RodRíGUeZ VALENCIA, "La Colegiata y la Catedral de Valladolid", Boletín de la Real Academia de Bellas Artes de la Purísima Concepción de Valladolid, número 25, 1974, p. 20.

${ }^{8}$ F. CHueCA GoITIA, La catedral de Valladolid. Una página del Siglo de Oro de la arquitectura española. Madrid, 1947, p. 30. 
ahora aportan nueva luz sobre la construcción tardogótica y la vida de sus maestros de obra: Diego de Riaño y Juan de la Cabañuela, y redefinen la labor de Rodrigo Gil de Hontañón en la misma.

\section{DIEGO DE RIAÑO Y LA COLEGIATA}

De la labor de Riaño como maestro de obras de la nueva colegiata apenas tenemos noticias ya que no se han conservado ni los acuerdos capitulares ni el libro de fábrica de esas fechas. Se sabe que modificó el plan de los cinco maestros al montar las torres de los pies sobre el primer cuerpo de capillas hornacinas y que inició las obras de cimentación no sin problemas, al dar con un manantial de agua y unos pequeños restos romanos. A la vez, se procedía a la compra de solares para la construcción de la nueva iglesia ${ }^{10}$.

La obra avanzaba con dificultad; el dinero procedente de las arcas reales había disminuido, si bien se habían realizado importantes donaciones de particulares como la Duquesa de Béjar ${ }^{11}$. El Concejo de la villa también había favorecido la construcción al acordar el cierre de algunas

\footnotetext{
${ }^{9}$ J. Antolínez De Burgos, Historia de Valladolid..., p. 194; M. SANGRADOR Y VÍTORES, Historia de la Muy Noble y Leal Ciudad de Valladolid, desde su más remota antigüedad hasta la muerte de Fernando VII. 2 Tomos, Valladolid, 1854; A. BUSTAMANTE GARCÍA, La arquitectura clasicista del foco vallisoletano (1561-1640). Valladolid, 1983, pp. 114-115. Sobre los restos encontrados: J. AgAPITO Y ReVILla, "Para la historia...", p. 74.

${ }^{10}$ Compromiso firmado entre el cabildo catedralicio y Alejo Sánchez, nombrando tasadores de la casas que éste tiene arrendadas en la calle "de la cárcel del señor abad", que deben ser derribadas para la nueva iglesia. A.H.P.Va., Leg. 6, 1527, ante Cristóbal Montesino.

${ }^{11}$ En 1532 el cabildo da poder al canónigo Diego Rodríguez de Alcaraz para que pueda cobrar los 1.000 ducados donados por la duquesa para la obra de la nueva iglesia. A.H.P.Va., Leg. 8, fol. 424, ante Cristóbal de Montesino.
}

calles próximas durante el plazo de dos años $^{12}$.

Pero los problemas fundamentales se derivaban de las ausencias del maestro, encargado entonces de otras importantes obras en la lejana Sevilla, donde consta ya como maestro de obras del ayuntamiento hispalense el 29 de marzo de 1527, y a cargo de la construcción de la catedral al menos desde el último trimestre de 1526, antes incluso de la colocación de la primera piedra en Valladolid. Las nóminas de las obras sevillanas nos hablan de su presencia más o menos continuada en la ciudad durante 1528, el mes de febrero y el último trimestre de 1529, y enero de $1530^{13}$. En 1531, ocupado en la catedral sevillana, pedía a dos peones de la obra que acudiesen a "Salamanca y Valladolid y Segovia, Peñafiel y Granada y Córdoba" a buscar maestros para trabajar el alabastro de las capillas de la catedral ${ }^{14}$. Ese año se paralizaban las obras de la catedral hispalense hasta 1532, parón que aprovecha el maestro para acudir a Valladolid ya que sabemos que en 1531 estuvo en la ciudad pues se ocupó en realizar un informe sobre la iglesia de Santa María La Antigua ${ }^{15}$. Tras la reanudación de la obra del ayuntamiento sevillano en junio de 1532, el maestro está documentado en el sur en febrero, abril y mayo de 1533 y entre marzo y mayo de 1534. Consta que durante julio y agosto de 1534 sus procuradores reciben un poder para cobrar deudas del maestro lo que podría indicar que éste se

-

12 A.H.P.Va., Leg. 10, fol.388. Año 1534.

13 A.J. MORALES, La obra renacentista del Ayuntamiento de Sevilla. Sevilla, 1981, pp.30 y ss.

${ }^{14}$ A.J. MORALES, "La arquitectura de la catedral de Sevilla entre los siglos XVI, XVII y XVIII", en La Catedral de Sevilla, Sevilla, 1991, p. 180.

${ }^{15}$ Entonces consta como "cantero de la obra de Santa María Mayor", cit. J.J. MARTín GONZÁLEZ Y J. URREA FERNÁNDEZ, Catálogo monumental de Valladolid. T.XIX, Monumentos religiosos de la ciudad de Valladolid (Catedral, parroquias, cofradias y santuarios), Valladolid, 1985, pp. 172 y 177. 
encontraba fuera de Sevilla o tenía previsto ausentarse. De hecho, murió en Valladolid el 30 de noviembre de $1534^{16}$. El 17 de diciembre se procedió a realizar el inventario de los bienes del maestro que habían quedado en Sevilla, actuando como sus procuradores Martín de Gainza (que le sustituiría como maestro mayor de la magna hispalense) y Juan Picardo ${ }^{17}$. Además de constar deudas por obras realizadas para la santa iglesia de Sevilla, el monasterio de San Francisco y las iglesias de Carmona, Arcos, Aracena, Aroche y Aznalcóllar, entre otras, del documento se deduce la sorprendente pobreza material que envolvía al "maestro mayor de las obras de cantería de la santa yglesia de sevilla". Del reducido inventario de su ajuar doméstico, destacan una única referencia a "cierta herramienta de su officio" y "ciertos papeles de debuxos de su

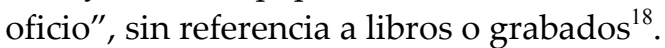

Nada más sabíamos hasta ahora sobre la continuación del nuevo templo vallisoletano (se ha supuesto que estuvo para$\mathrm{do}^{19}$ ) hasta el nombramiento de Rodrigo Gil de Hontañón como maestro mayor de la misma el 30 de agosto de 1536, aunque de hecho actuaba como tal desde mayo de ese año ${ }^{20}$. La localización de un pleito inter-

\footnotetext{
${ }^{16}$ J. GESTOSO Y PÉREZ, Historia y descripción de la sacristía mayor de la Catedral de Sevilla y de las preciosidades artísticas que en ella se custodian. Sevilla, 1892, p. 8.

${ }^{17}$ Ambos fueron colaboradores de Riaño en las obras del Ayuntamiento de Sevilla y de su catedral. Véase: A.J. MORALES, "El Ayuntamiento de Sevilla: maestros canteros, entalladores e imagineros", en Laboratorio de Arte, 4 (1991), pp. 69, 74.

${ }^{18}$ Así lo recoge Morales (A.J. MORALES, La obra renacentista..., p. 37), quien cita a J. HERNÁNDEZ DÍAZ, Arte y artistas del Renacimiento en Sevilla. Col. Documentos para la Historia del Arte en Andalucía. Tomo IV. Sevilla, 1933, p.11. La referencia de archivo actual del inventario es A.H.P.Sevilla, Secc. Protocolos Notariales, Leg. 3307.

19 A. CASASEca CASASECA, Rodrigo Gil de Hontañón (Rascafría, 1500-Segovia, 1575). Salamanca, 1988, p. 96.

${ }^{20}$ El documento del contrato como maestro mayor de Rodrigo Gil (A.H.P.Va., ante Cristóbal Montesino,
}

puesto ante la Real Chancillería de Valladolid por el maestro de cantería Juan de la Cabañuela en agosto de 1535 nos aporta valiosa información sobre la obra de la colegiata, a la vez que nos permite conocer nuevos detalles de la vida y trabajo de Diego de Riaño ${ }^{21}$.

Juan de Cabañuela era el 30 de agosto de 1535 "cantero y aparejador de la yglesia mayor desta noble ciudad de valladolid", en la que figura como residente y es$\operatorname{tante}^{22}$. En esa fecha sus procuradores presentaban una demanda ante la Real Chancillería de Valladolid en la que reclama la parte que le correspondía de la herencia del difunto maestro mayor de la colegiata vallisoletana Diego de Riaño, a la sazón su tío ${ }^{23}$. Los demandados por Cabañuela eran los otros herederos de Riaño: Lucía y Elvira González, hermanas del difunto, y los herederos de Juana y Mari, hermanas di-

\section{-}

año 1536, fols.222-223) fue publicado en J. AGAPITO Y ReVILLA, "Para la historia...", pp.231 y ss. Un extracto en N. AlONSO CORTÉS, "Miscelánea vallisoletana...", pp. 1-2.

${ }^{21}$ A.R.CH.V., Pl. Civiles, Fernando Alonso (F), Caja 891 , exp.2.

22 Nacido hacia 1510, se documenta su estancia en Valladolid desde 1532 vinculado ya a la fábrica catedralicia pues vivía en una casa junto al taller de los canteros. Era primo segundo del también cantero Juan del Valle y posiblemente por sus relaciones familiares custodiaba en un arca "ciertas muestras de papel de su oficio de cantería". Cit. M.J. REDONDO CANTERA, "Los arquitectos y canteros del entorno de Rodrigo Gil...", p. 25.

23 "...digo que a my noticia es venydo como v.m. mando a Juan garcia de totero poseedor de los bienes que quedaron e finaron de diego de riaño mi tio ("de my parte" entre líneas) que me le a...diese con ellos y los diese y entregase a juan de hornedo procurador de ciertos herederos que se dizen ser del dicho diego de riaño my tio ("e los my parte" entre líneas) y porque v.m. hallara por verdad que yo my parte soy (tachado) es uno de los legitimos herederos del dicho diego de riaño mi tio de my parte el qual murio abintestado e syn hazer testamento y hera hermano de la madre de my parte ya defunto....". 
funtas de Diego ${ }^{24}$. De este modo, Cabañuela demandaba a su propia familia representada por Juan de Hornedo, su cuñado y posiblemente también cantero ${ }^{25}$. La familia procedía del lugar de Hornedo en la Junta de Cesto, cercano a las poblaciones de Solórzano, Riaño, Riotuerto y Entrambasaguas, todas ellas de larga tradición canteril para

\section{-}

${ }^{24}$ Parte de los herederos de Riaño aparecen ya citados en J. HERnÁNDEZ DíAZ, Arte y artistas del Renacimiento en Sevilla..., VI, p. 11.

25 "Sepan quantos esta carta de poder vieren como nos luçia Gonzalez viuda muger que fui de Juan de la puente vecino del lugar de aças ques en la junta de cesto y elvira gonzalez vecina del lugar de hornedo ques en la junta de cudeyo como hermanas legitimas que somos de diego de riaño defunto natural del dicho lugar de hornedo e my hermana muger de juan de la cabañuela vecino del lugar de riaño hija de juana gonzalez defunta hermana legitima del dicho diego de riaño defunto e juana muger de pedro de hornedo hija legitima de maria gonzalez hermana del dicho diego de riaño defunto" por virtud de una diligencia del alcalde de la junta de cudeyo "por estar ausentes de la tierra los dichos nuestros maridos"... y "maria cabañuela mujer legitima que soy de juan hornedo vecino de riaño, hija que soy de juana gonzalez hermana del dicho diego de riaño defunto".... dan poder a Juan de Hornedo para que las represente en dicho pleito. Firmado en Hornedo, 2 de junio de 1535. Erróneamente Camón cita a Pedro de Riaño, cantero natural de Riaño y trabajador en las Casas Capitulares de Sevilla, como hermano de Diego (J. CAMÓN AZNAR, La arquitectura y la orfebrería española del siglo XVI. Summa Artis, vol. XVII, Madrid, 1959, p.329, cit. A.J. MORALES, La obra renacentista del Ayuntamiento de Sevilla..., p. 29). Un Juan de Hornedo cantero natural de Hornedo, en 1551 se compromete a hacer una ventana de cantería en la iglesia del Salvador de Abezames conforme a sus propias condiciones. Navarro Talegón indica que podría ser miembro de la familia de canteros a la que pertenecía G. de Fornedo que en 1480 trabajaba en la iglesia de Matilla la Seca. Éste y Alonso de Hornedo "el viejo", sus hijos Alonso, Pedro y este Juan -coautor de la torre de Pozoantiguo-, figuran en el Catálogo Monumental de Toro y su alfóz, Zamora, 1980, pp.52, 370, 376. Entonces Navarro Talegón los daba como "Arnedo". Corrige su error en J. NAVARRO TALEGÓN, "Documentos inéditos para la Historia del Arte en Zamora", Studia Zamorensia, 4 (1983), p. 88. Otro Juan de la Cabañuela, maestro de cantería, vecino de Pámanes, en 1548 se concertaba con el convento de Santa Clara de Santander para ser su apoderado (A.R.Ch.V., Pleitos Civiles, Fernando Alonso (F), caja 210, exp. 4). esas fechas del siglo XVI. El arquitecto también era natural de dicho lugar aunque hasta ahora se suponía que el apellido Riaño aludía al toponímico como solía ser habitual en la época ${ }^{26}$. Otros historiadores han supuesto su origen en la ciudad del Pisuerga ya que allí se localizaban tres Riaño además del arquitecto $^{27}$. Diego era el único hijo varón del matrimonio formado por Juan Gómez de Riaño y María González y a la hora de su muerte no se le conocía matrimonio y no dejaba herederos legítimos ni naturales. La muerte le sorprendió trabajando en Valladolid, donde fue enterrado $\sin$ testar $^{28}$.

Juan de la Cabañuela además reclama la cantidad de 36.000 maravedíes "de los quales a my parte se los presto a los demas e quedo deviendo del tiempo que le servio e los gasto en su servicio yendo a ver los

-

${ }^{26}$ Sojo y Lomba desconocía el lugar de origen del maestro pero publicaba la referencia de que un Pedro de Riaño natural de Riaño, había prestado dinero a Diego (F. SOJO Y LOMBA, Los maestros canteros de Trasmiera. Madrid, 1935, p. 152). Este dato sirve a Morales para establecer el origen de Diego en el pueblo de Riaño. Como él, otros muchos hemos creído en el toponímico ( $\mathrm{M}^{\mathrm{a}}$ C. GONZÁleZ ECHEGARAY; M.A. ARAmburu-Zabala; B. AlONSO RuIZ y J.J. POlO SÁNCHEZ, Artistas cántabros de la Edad Moderna. (Diccionario biográfico-artístico). Santander, 1991, pp. 557-558) y M.J. REDONDO CANTERA, "Los arquitectos y canteros del entorno de Rodrigo Gil...", p.25.

${ }^{27}$ En 1498 se cita a un Lorenzo de Riaño que hace tubos de alfarería para fuentes; existe otro Diego de Riaño en 1596 informando sobre el cimborrio de San Francisco de Medina de Rioseco y un Juan de Riaño en 1603 trabajando en Tudela de Duero. (Cit. J. AGAPITO Y REVILLA, "Para la historia...",p. 225).

${ }^{28}$ En la probanza del pleito realizada el 13 de noviembre de 1536 Andrés de la Sota, carpintero vecino de Hornedo de edad de 40 años, declaraba que "estaba este testigo en la villa de portillo oyo decir como el dicho diego de riaño contenydo en la dicha pregunta hera fallescido desta presente vida e que abia fallescido en la yglesia mayor de esta villa e tenia la obra de las dicha yglesia ...e vio su sepultura donde se enterro". Según dicho testigo había fallecido el día de San Andrés de hacía dos años sin hacer testamento. No le conoció mujer ni hijos. 
caminos a costa de my parte en los negocios tocantes al dicho su tio" como consta en un conocimiento firmado por el propio Riaño que se presenta como prueba en la causa ${ }^{29}$. De este primer documento se deduce que Cabañuela trabajaba para Riaño en la obra de Valladolid sirviéndole en encargos de confianza como su aparejador, realizando también viajes a La Montaña, donde residía la familia de ambos, o a Sevilla, donde el maestro mantenía la dirección de las obras del nuevo ayuntamiento y de la catedral. De hecho, sabemos por documentación sevillana que el maestro pasaba ocho meses en Sevilla y cuatro en Valladolid ${ }^{30}$; esta circunstancia se debía mantener desde que en 1526 fuese nombrado Maestro Mayor de la Catedral y al siguiente iniciase la obra de las Casas Consistoriales, obras que mantendría a su cargo también hasta su muerte. El compaginar obras en tan lejanas ciudades obligó al cabildo vallisoletano a retirarle su salario de maestro mayor en 1532, ya que en ese año el sevillano mandó darle 50 ducados "por lo que había perdido del salario que gozaba en Valladolid"31. En una de estas obras, probablemente la vallisoletana, debieron trabajar los canteros que el 22 de

-

29 "Conosco yo diego de Riaño que debo a vos Juan de la cabañuela my sobrino treynta e seys myll maravedies por razon que algunos dellos me los prestasteis en dineros y que pasaron de vuestro poder al mio y los otros me los abeys servido en caminos y en costas que se os an regresado por amor de my en yr a la montaña y para yr a sevylla por cosas que a mi me conplian a ciertos negocios que yo hos rogue que fasedes y por que fue todo a vuestra costa os debo los dichos treynta e seys myll maravedies... en valladolid a siete de agosto de myll e quinientos e treinta e tres años/. Diego de Riaño".

${ }^{30}$ J. AgAPITO Y REVILLA, "Para la historia...", p. 224. Aunque no podemos contabilizar las estancias vallisoletanas del maestro, las cuentas sevillanas confirman que Riaño pasaba más tiempo en el Sur. ( J. HERNÁNDEZ DíAZ, Arte y artistas del Renacimiento en Sevilla..., pp. $9-11)$.

${ }^{31}$ J. MARTí Y MONSÓ, "La capilla del doctor Corral en la iglesia de la Magdalena de Valladolid", Boletín de la Sociedad Castellana de Excursiones, III (1907-8), p. 281. noviembre de 1535 también reclamaban dinero a los herederos de Riaño representados por Hornedo; se trataba de Juan de Villasante ("cantero vecino del lugar de hornedo") y Juan de Secadura ("cantero vecino del lugar de entrambasaguas").

Todas las partes en conflicto acordaron reunirse el último día de enero de 1536 y acatar la decisión que tomasen los jueces Pedro del Casar y Andrés de la Lastra, vecinos de Hornedo. El día señalado los jueces decidieron que:

"luego que el dicho Juan de Hornedo vaya a valladolid y el dicho juan de la cabañuela por el sea requerido dentro de nueve dias primeros siguientes de yr entregue el dicho juan de la cabañuela al dicho juan de hornedo dos muestras que fueron en su poder que dexo el dicho diego de riaño la una de la casa de consistorio de Sevilla y otra del lugar de aroche para que las lleve el dicho juan de hornedo para sevilla porque diz que no quieren dar e pagar ciertos maravedis que debian a diego de riaño sin que se las den

Otro si mandaron que porque la hazienda e devda que parescieren deverse en sevilla e otras partes se cobren bien e a la menos costa que ser pueda que el dicho juan de la cabañuela de e otorge poder al dicho juan de hornedo para cobrar su parte juntamente con la de los otros herederos e de todo favor e ayuda que sea neçesario para se cobrar e que luego desenbargue en valladolid todos los maravedies e bienes que a su pedimento estan enbargados e favores os ayude en lo que pudiere de palabra e de obra como todo y ello a menos costa

Otro si mandaron que cerca de ciertas alajas e cordones e cofia y otras cosas que dexo el dicho diego de riaño al tiempo que murio que diz que fueron a poder del dicho juan de la cabañuela que lo aya e tenga e goze e lleve libremente sin acodir 
con nynguna cosa dello al dicho juan de hornedo ni a los otros herederos...".

Sobre la deuda de 50 ducados de oro que reclamaba el cantero Juan de Secadu$\mathrm{ra}^{32}$ dispusieron la cantidad de 8.000 maravedíes "visto lo que el dicho juan de secadura habia estado preso en la carcel rreal de valladolid por cavsa de la acusacion que la habia dado diego rroyz de peralacia e su muger por cosas que avia fecho e negociado por el dicho diego de riaño e venida de valladolid a trasmyera e vis todo lo demas que ver se devia a tenido un memorial de costas que el dicho juan de secadura antellos presento vista la calidad e oficio del dicho juan de secadura..."

Respecto a la demanda de Villasante en nombre de Juan Fernández vecino de Hornedo "atento al tiempo que estuvo preso en la carcel de la chancilleria real de valladolid e visto la venyda que vino de valladolid a trasmyera y como por rrazon de negocios e cosas e negocios del dicho diego de riaño ubo acusado ...de la muger de diego rruyz de peralacia como se dio contra el sentencia en rebeldia e para se salbar della tubo necesidad de se presentar en la carcel de la chancilleria atento el oficio e calidad e negocios del dicho juan fernandez..." fallaron que se le darían 10 ducados de oro a cuenta de los bienes de Riaño embargados en Valladolid.

Pero el pleito seguía su curso en la Real Chancillería; por la probanza realizada el 13 de noviembre de 1536 sabemos que "a la muerte de Riaño dejo muchos bienes muebles y raices en muchas partes, especialmente los bienes están depositados en poder de Juan García de Cotero, carpintero

\footnotetext{
${ }^{32}$ La Real Chancillería de Valladolid en 1524 emite una ejecutoria sobre Juan de Secadura, cantero, vecino de Segovia, sobre el pago a éste de las obras de puente, arcos, humilladero y otras cosas que hizo para el concejo de Medina del Campo (A.R.Ch.V., Registro de Ejecutorias, caja 0370.0015).
}

vecino de valladolid". Quizá estemos ante los bienes que echábamos de menos en el inventario sevillano. Mientras, asistimos lentamente al cobro de dineros por parte de los herederos. El 26 de marzo de 1537 los representados por Juan de Hornedo reciben de Juan de Escalante, procurador del difunto Riaño, la cantidad de 36.750 maravedíes del dinero de Riaño ${ }^{33}$. Aunque esa cantidad se asemejaba mucho a la demandada por Cabañuela, no se consiguió solucionar los problemas familiares y el 22 de enero de 1538 en Burgos Cabañuela (autotitulándose "maestro de canteria vecino de la muy noble y leal villa de valladolid maestro de la obra de la yglesia colegial de santa maria la mayor de la dicha villa") daba poder a los procuradores de causas Agustín de Medina, Pedro de Castro y Juan de Burgos para los pleitos que seguía manteniendo en la Chancillería de Valladolid con los herederos de Diego de Riaño.

Desconocemos cómo acabó la historia ya que la ejecutoria del pleito no ha sido localizada, pero nos interesa destacar el que en enero de 1538 Cabañuela fuese el maestro de la colegiata iniciada por su tío. Completamos así la información aportada por Martí y Monsó cuando dio a conocer otro pleito en el que se vio inmerso Cabañuela por el que en diciembre de 1541 se declaraba, de nuevo, maestro de la colegiata vallisoletana ${ }^{34}$. Sin duda, las múltiples obligaciones del cada vez más atareado Rodrigo debieron influir en el ánimo del cabildo que no debió ver con buenos ojos las ausencias de su maestro, obligado por el contrato a residir en la ciudad al menos dos meses al año. De hecho, en 1538 no consta la presencia de Rodrigo en Valladolid, si bien sabe-

\footnotetext{
33 J. HERnÁNDEZ DíAz, Arte y artistas del Renacimiento en Sevilla..., pp. 11.

${ }^{34}$ J. MARTí y MONSÓ, "La capilla del doctor Corral..., p. 281. Esta antigua referencia ha pasado desapercibida para los que se han ocupado de la colegiata vallisoletana.
} 
mos que al año siguiente estuvo en la ciudad ya que visitó la iglesia de La Antigua ${ }^{35}$. Las monografías dedicadas al maestro Hontañón señalan que los seis estadios (doce metros) que vio levantados Antolínez de Burgos en el nuevo templo vallisoletano se debían a la maestría de Rodrigo, si bien en los libros de fábrica conservados (el primero comienza en 1547) no consta ni la maestría de Rodrigo ni la de Cabañuela; de hecho, no constan pagos de salarios a ningún maestro de obra, y lo que resulta aún más sorprendente es que no conste ningún apunte del cabildo en 1577 por la muerte del supuesto maestro mayor de la obra, Rodrigo Gil, evidenciando que ya no lo era. Las únicas referencias al maestro Hontañón en las actas capitulares datan de 1550 y 1568. En la primera, febrero de 1550, el arquitecto daba poder al carpintero Pedro Gil de Mazavellosa para que se encargase de cobrar del cabildo su salario de maestría y los jornales que le adeudaban por los días que se ocupó en "visitar la obra y edificio". No debió conseguirlo el carpintero por lo que de nuevo a finales de dicho año el entonces aparejador de la obra, Juan de Ribero, reclamaba dineros que se debían a Rodrigo Gil, acordándose que se pagara desde diciembre de 1550 hasta el día de Reyes de $1551^{36}$. En la segunda referencia, de 1568, el arquitecto daba su parecer con Francisco de Salamanca sobre la mudanza del coro a la nave, sin que se le cite como el maestro de la obra ${ }^{37}$. De todo ello se deduce la maestría del Hontañón en dos periodos diferentes:

-

${ }^{35}$ A. CASASECa CASASECA, Rodrigo Gil de Hontañón..., p. 322.

${ }^{36}$ La noticia de Mazavellosa en A.H.P.Va., Leg. 122, fol. 21-24 vto. La noticia de Juan de Ribero en A.C.V. Actas Capitulares, 1547-79, s/f. Ambas en M.J. REDONDO CANTERA, "Los arquitectos y canteros del entorno de Rodrigo Gil...", pp. 24, 57.

${ }^{37}$ J. ZURITA NIETO, Apuntes documentales sobre el año de la muerte del Conde Don Pedro Ansurez acerca de su sepultura y epitafio y aniversario en la S.I.M. de Valladolid. Valladolid, 1918, pp. 13-14. de 1536 a 1538 y entre 1550-1551, manteniendo relación posterior con el cabildo, si bien ya no como su maestro de obras. Cabañuela lo fue entre 1538 y 1541.

La hipótesis más lógica indica que Rodrigo, posiblemente obligado por el cabildo, dejase la dirección en manos de Cabañuela. Las ventajas que proporcionaba Cabañuela frente al Hontañón eran evidentes si tenemos en cuenta su residencia en la ciudad y su conocimiento de la colegiata posiblemente desde sus comienzos, siendo aparejador de la misma antes de la llegada de Rodrigo. Puede incluso que fuese Cabañuela el aparejador "abil y suficiente para la dicha obra" que estaba obligado a elegir Rodrigo, según su contrato de 1536, si bien en la firma de su contrato figura Juan de Ribero, documentalmente contrastado como aparejador de la obra en $1550^{38}$.

Si intentamos ahora una reconstrucción de la historia constructiva del templo sabemos que durante dichas maestrías se levantaron los muros de la Epístola, parte de la torre y las dos primeras capillas hornacinas, quedando iniciada la tercera, más o menos como lo encontró Juan de Herrera al hacerse cargo de la obra y lo dibujó Diego de Praves ${ }^{39}$. El libro de fábrica nos habla de obras en la iglesia en $1540^{40}$. También sabemos que el templo sufrió un incendio en 1548, afectando de manera especial a la sala de la librería que caía sobre la Plaza del León $^{41}$. Sobre esta misma plaza se abría el

\footnotetext{
${ }^{38}$ M.J. REDONDO CANTERA, "Los arquitectos y canteros del entorno de Rodrigo Gil...", p. 57.

39 A. BUSTAMANTE GARCÍA, La arquitectura clasicista del foco vallisoletano..., pp. 116-117.

${ }^{40}$ La referencia es indirecta: se trata del arrendamiento de las casas de la fragua con sus herramientas que la iglesia tiene junto a las obras de la iglesia nueva. A.H.P.Va., Sig. 16, 1540, fols.369-371.

${ }^{41}$ El 5 de junio de 1548 acordaron que se tome lo que fuese menester para aderezar la librería del arca del tesoro que se quemó. El 24 de enero de 1550 fue acordado por el cabildo "que lo que toca al incendio de
} 
claustro que también comunicaba con la "obra nueva", tal y como se puede comprobar en el plano de las tres iglesias mayores de Valladolid que dio a conocer Juan Agapito y Revilla ${ }^{42}$. A mediados del siglo se acuerda cerrar todas las entradas a la obra, demostrando que ésta seguía sin funcionar; probablemente el parón coincidiría con los últimos pagos al maestro Rodrigo, liquidando así todo lo referete a la cantería del nuevo templo. De hecho, los escasos trabajos de cantería que se realizaron en la iglesia afectaban a las capillas de la vieja colegiata gótica, y a trabajos que bien podían realizar canteros y carpinteros, sin que fuese necesaria la presencia en nómina de un arquitecto. Se trataba del aderezo de las capillas de San Sebastián, San Ildefonso, del Sacramento, de San Miguel, de San Marcos o de las Ánimas, la obra de cantería del sagrario, el alzar las gradas de la sacristía, "adereçar las colunas que estaban quebradas que adobó Escalante seis reales", etc. ${ }^{43}$. A la obra nueva corresponde las treinta y un tapias que se construyen en 1552, los gastos ocasionados en 1553 en la llamada "puerta trasera" o "puerta nueba" donde durante los meses de mayo a agosto, nuevas tapias y un cobertizo de cantería con

la yglesia" se comisionó al prior y al licenciado Balboa "y que den dello parte al señor abad para que ellos agan y corten por donde quisieren". Están hablando "sobre la quema de la sala de la librería". A.C.V. Libro Secreto del prior y cabildo desta yglesia colegial de Valladolid, desde 1547.

${ }^{42}$ J. AGAPITO Y REVILLA, “Tres trazados de la iglesia mayor de Valladolid en un dibujo", en Diario Regional, 28 de abril de 1943, cit. F. CHUECA GOITIA, La catedral de Valladolid..., p. 34. Se confirma así la proximidad de la obra nueva con el viejo claustro, en contra de la opinión de A. BUSTAMANTE GARCÍA, La arquitectura clasicista del foco vallisoletano ..., p. 114.

43 A.C.V., Libro de fábrica, 1548-1555. En 1552 consta que "hizieronse en la obra nueba treinta y una tapias a cinco reales". Debe tratarse del Juan de Escalante, cantero primero a las órdenes de Riaño y después habitual de la cuadrilla de Rodrigo Gil. Sobre él véase también M.J. REDONDO CANTERA, "Los arquitectos y canteros del entorno de Rodrigo Gil...", p. 45. piedra de Villanubla. Estos trabajos corren a cargo de canteros en su mayoría anónimos y carpinteros a las órdenes de Pedro del Valle ${ }^{44}$. En 1557 don Alonso Cabezas testaba fundando una capilla dedicada a Santa Inés (luego de la Concepción) en la nueva colegiata vecina de la del canónigo Santisteban $^{45}$. Juan de Ballesteros continuaba trastejando el templo, mientras se reforzaban los apoyos de la claustra en $1565^{46}$.

\section{LA COLEGIATA DE EL BIERZO}

La carrera profesional de Cabañuela, avalada por su relación familiar con Riaño, le encumbró a la maestría catedralicia y le proporcionó los contactos necesarios para realizar buenos contratos, como la capilla de Pedro de Toledo en El Bierzo o la capilla del Doctor Corral en La Magdalena de Valladolid. Pese a ello, su trayectoria está salpicada de obras con problemas que acabaron en numerosos pleitos y le obligaron a finalizar sus días realizando trabajos de menor categoría como un maestro de cantería más de cuantos trabajaban en la provincia de Valladolid, demostrando que no estaba a la altura de tales encargos.

Siendo aún aparejador de la colegiata vallisoletana, en 1535 acudió junto con Hortuño de Marquina y Juan de la Puente al remate de la obra de la iglesia parroquial de Cigales (Valladolid), entonces perteneciente al señorío de Hernando de Toledo ${ }^{47}$. Puede

\footnotetext{
${ }^{44}$ En algunos casos se recoge el nombre del oficial de cantería como "Alisas", cantero.

${ }^{45}$ V. RODRÍGUEZ VALENCIA, "La Colegiata y la Catedral de Valladolid..., p. 35.

${ }^{46}$ A.C.V., Libro de fábrica, 1562-1581, fol. 99 vto. Año 1565. "Primeramente di seis reales a Juan vrquiçio y a lastras canteros que dieron su parezer firmado sobre el reparo y adrezo -sic- del paño de la claustra". (Al margen pone "traza").

${ }^{47}$ F. HERAS GARCÍA, Arquitectura religiosa del siglo XVI en la primitiva Diocesis de Valladolid. Valladolid, 1975, p. 91. Sobre Juan de Escalante véase también: J. CASTÁn LANASPA, Arquitectura gótica religiosa en Valla-
} 
ser esta la razón de que fuese elegido por el poderoso don Pedro de Toledo, marqués de Villafranca y Capitán General del Reino de Nápoles, para continuar la construcción de su capilla en la colegiata de Villafranca del Bierzo (León). El Alba, inclinado a gustos más clásicos en sus obras italianas, había conseguido en 1532 la independencia del priorato de Corniego respecto de la diócesis de Astorga y había iniciado el nuevo templo, cuyo proceso constructivo parece que seguía muy de cerca. De hecho, el templo había sido trazado en torno a 1539 por Fray Martín de Santiago (arquitecto dominico vinculado a Salamanca y a la Casa de Alba) siguiendo las indicaciones de los marqueses. El resultado es un edificio de estructura muy común y poco innovadora para esas fechas del siglo: cabecera ochavada cubierta con sencilla bóveda de nervios rectos, crucero que no sobresale en planta y naves a la misma altura al modo de las iglesias salón. El modelo de cabecera profunda y ochavada remite a esquemas del tardogótico más sencillo, mientras que la cúpula del crucero nos habla ya de otros gustos a la clásica; por su parte, la solución de iglesia salón sobre grandes pilares cilíndricos supone uno de los grandes modelos constructivos de la arquitectura de la época: el numeroso conjunto de iglesias mal llamadas "columnarias" $^{48}$ construidas en torno a estas fechas en el ámbito de Rodrigo Gil de Hontañón y derivadas de los modelos empleados a co-

dolid y su provincia (siglos XIII-XVI), Valladolid, 1998, p. 685.

${ }^{48}$ Desde que en 1923 Elías Tormo acuñó el término de iglesia "columnaria" para referirse a las iglesias de naves a la misma altura con columnas como soportes, el concepto ha tenido una gran aceptación entre la historiografía española como evidencia el que aún hoy se sigue utilizando, aunque su significado continúa sin delimitarse claramente. Sobre el concepto de iglesia salón véase B. ALONSO RUIZ, Arquitectura Tardogótica en Castilla: los Rasines. Santander, 2003, pp. 107-138. mienzos de la centuria por arquitectos como Juan Gil de Hontañón ${ }^{49}$.

El contrato con Juan de la Cabañuela se firmó en Valladolid el 10 de septiembre de 1541, y establecía que la obra debía realizarse en un plazo de cuatro años por un precio de 10.500 ducados y a vista de oficiales. Entonces los fiadores de Cabañuela fueron Luis de la Torre (mercader, vecino de Valladolid), Juan García del Otero (carpintero, vecino de Valladolid), Hernando de Saravia (vecino del valle de Solórzano, en Cantabria), Pedro Vellala (vecino de Hornedo), Andrés de la Lastra (vecino de Hornedo) y Juan de Villasante (cantero vecino Valladolid) ${ }^{50}$. Poco y mal debió trabajar Cabañuela ya que muy poco después, el 7 de enero de 1542, el marqués formalizaba su pleito en la Real Chancillería contra Juan de la Cabañuela (estante en la villa) y su fiador. Al mes siguiente, Cabañuela recibía la cantidad de 7.432 maravedís por su trabajo en la obra, puede que en un intento del marqués de liquidar cuentas con el maestro y cerrar su intervención en la obra $^{51}$.

-

${ }^{49}$ Por ejemplo, entre 1502 y 1503 Juan Gil de Hontañón diseñaba una nueva colegiata para la villa de Medina del Campo (Valladolid); San Antolín se concibió como una iglesia de tres naves divididas en tramos cuadrados -lo que por sí sólo resultaba una gran novedad- sin transepto más una cabecera rectangular a la que posteriormente se añadieron dos capillas. También en Valladolid pero en la iglesia de Santa María de Mediavilla de Medina de Rioseco, se construyó a comienzos del siglo un templo que combina naves salón de tramos perlongados con una cabecera profunda.

${ }^{50}$ No se han conservado escrituras de Juan de Santiesteban, por lo que desconocemos las condiciones del contrato más allá de las recogidas en la ejecutoria del pleito.

${ }^{51}$ Ma D. CAMPOS SÁNCHEZ-BORDONA, "La colegiata de Villafranca del Bierzo. De fray Martín de Santiago a Guillermo Casanova", en Actas del Congreso Rodrigo Gil de Hontañón. El arte de la cantería, Santander, 2003, p. 127. 
Según informa la ejecutoria del pleito $^{52}$, en el contrato entre el marqués y Cabañuela, éste constaba de nuevo como "maestro de la canteria de la ovra de la yglesia colegial de santa maria la mayor de la dicha villa de valladolid". El contrato era para hacer "una capilla en la yglesia colejial de nuestra señora de santa maria de curnyego de la villa de villafranca", la cual debía "de ser la capilla mayor de la dicha yglesia". La obra podía pararse si el marqués "no fuese contento quel dicho Juan de la Cabañuela travajase en la dicha obra conforme a las condiciones que estavan en las escrituras", lo que ocurrió cuando don Pedro pidió a la justicia ordinaria que mandase al dicho maestro "que no entendiese mas en la dicha ovra e alcase mano della conforme al capitulo de la dicha escritura". Ya en 1541 el mayordomo de la fábrica había llamado a peritos para inspeccionar la marcha de la obra, ante las imperfecciones que se observaban en ella. Los trasmeranos Lope García (¿de Arredondo?), Juan Gutiérrez (¿de Buega?) y Fernando del Solar, junto con Francisco Juli (del que más tarde hablaremos), emitieron su informe ya en 1542, coincidiendo en que estaba mal cimentada, realizada con materiales inadecuados ("piedra de guijarro y menuda") y sin seguir las condiciones establecidas por fray Martín ${ }^{53}$. Debido a este desastre interviene de nuevo fray Martín dando nuevas condiciones para la obra, que se comienza de nuevo a cargo de los maestros -también procedentes de Salamanca- Juli y Diego de Torres que levantarían la capilla mayor y el crucero ${ }^{54}$. En la década de los sesenta la obra estaba en

\footnotetext{
${ }^{52}$ A.R.Ch.V., Reales Ejecutorias, C. 741/15.

${ }^{53}$ A.H.N. Secc. Consejos, Leg. 15570, fols.34-40, cit. Ma D. CAMPOS SÁNCHEZ-BORDONA, "La colegiata de Villafranca del Bierzo...", Santander, 2003, p.128. Transcritos en I. GARCíA TATO, “La Colegiata de Villafranca del Bierzo", en Bierzo (1999), pp. 152-158.

54 J.M. VOCES JOLÍAs, Arte religioso de El Bierzo en el siglo XVI. Ponferrada, 1987, p. 41.
}

manos de Baltasar Gutiérrez y en 1574 fue visitada por Rodrigo $\mathrm{Gil}^{55}$.

El pleito, mientras, seguía su curso. Cabañuela fue obligado a deshacer la obra a su costa por lo que en 1551, cuando se realizan los pareceres de los peritos, la capilla ya no existía. Por parte de Cabañuela emitió su parecer el maestro cantero Juan Díaz del Peral y por parte del marqués lo hizo Francisco Juli (maestro cantero vecino de Villafranca "de Galicia", natural de Borgoña y casado en la ciudad de Salamanca). El parecer de Juli, emitido el 30 de junio de 1551, nos informa de que la capilla hecha por Cabañuela en "la yglesia capitular e crucero de nuestra señora de cornyego de la dicha villa", antes de que fuese derribada podía valer 120 ducados incluyendo los materiales pero no el trabajo de los oficiales. Esta reducida tasación, incluida la calificación de obra "defectuosa y falsa", nos hablan de su escasa calidad. Pero en la ejecutoria, solicitada por Cabañuela, el 4 de agosto de 1551 se declara que "estava provado no solamente estava fecha conforme a las condiciones y traca a questava obligado pero aunque va falsa" y tenía problemas en muchas partes "no se podia edificar la dicha capilla sovre lo que tenya echo el dicho parte contraria". Los problemas parecían estar relacionados con la cercanía de la antigua abadía cluniacense de Curniego, que debía derribarse al levantarse la nueva fábrica.

\section{OTRAS OBRAS DE JUAN DE LA CABA-} ÑUELA

El 16 de noviembre de 1538 Cabañuela contrataba la obra de la capilla del Doctor Luis del Corral, Oidor del Consejo Real, y su mujer doña Juana Valdés, en la iglesia

55 A. CASTRO SANTAMARÍA, "Aportaciones al epistolario de Rodrigo Gil de Hontañón (Sobre la Catedral de Coria y la Colegiata de Villafranca)", Norba-Arte, XVII (1997), p. 50.
} 
vallisoletana de La Magdalena ${ }^{56}$. Las condiciones del contrato fueron publicadas por Martí y Monsó y en ellas se especifica que Cabañuela debía ajustarse a las trazas y condiciones proporcionadas por el mismo, cobrando por su trabajo 201.000 maravedíes. Actuaron entonces como sus fiadores los carpinteros cántabros Juan García de Otero (también de la cuadrilla de Riaño, como hemos visto) y Diego de Obregón, entonces vecinos de Valladolid. La obra se debía realizar en un plazo de dos años pero -co-mo casi siempre ocurría- la construcción continuaba mucho después, ya que existen noticias de la obra en 1545, estando ya concluida con rejas y retablo en $1547^{57}$. Martín González habla de la impericia del maestro y Castán Lanaspa achaca este retraso a las dificultades que pudo encontrar Cabañuela en la fábrica del templo, viéndose obligado a demoler la capilla de la segunda nave de la Epístola y parte de la torre aneja $^{58}$. Debido a estos retrasos y a los problemas que la nueva capilla había generado en el viejo templo parroquial a causa de la apertura de dos arcos de comunicación con la nave de la Epístola, la iglesia inició pleito con el arquitecto, llegando maestros peritos para informar de los males que sufría la construcción. Así, el 26 de julio de 1541 informaron sobre la marcha de la obra Hortuño de Marquina y Juan de Escalante, y a pesar de ser éste último viejo conocido de la cuadrilla de Riaño, los informes fueron desfavorables a Cabañuela. Se le acusaba de poner en peligro la capilla

-

${ }^{56}$ J. MARTí Y MONSÓ, "La capilla del doctor Corral...", pp.258-263, 279-287. Pleito ante la Real Chancillería de Valladolid, Taboada (F), envoltorio 282, tomo 2.

${ }^{57}$ J. MARTí Y MONSÓ, "La capilla del doctor Corral ...", p.259.

${ }^{58}$ J.J. MARTín GonZÁlez, "La iglesia de la Magdalena en Valladolid", Boletín del Seminario de Arte y Arqueología de Valladolid, XIV (1947-48), p. 206; J. CASTÁN LANASPA, Arquitectura gótica religiosa en Valladolid..., p.180. mayor del templo y su torre y se le obligaba a ponerle remedio encimbrando los arcos y ahondando los cimientos de la capilla. El 19 de diciembre Cabañuela ya estaba en prisión por no cumplir las condiciones impuestas por los informadores.

El resultado final fue la necesidad imperiosa de reconstrucción del viejo templo parroquial, lo que se llevó a cabo a partir de 1563 con dineros del obispo de Palencia y Sigüenza y virrey de Perú don Pedro de La Gasca ${ }^{59}$ y traza de Rodrigo Gil ${ }^{60}$. Debido a esta reconstrucción, la capilla ha perdido los arcos originales que la comunicaban con la antigua nave de la Epístola y que generaron el problema constructivo. La capilla resulta un espacio de considerable menor altura que el templo, sus dos espacios rectangulares se cubren con crucería de terceletes y combados formando un sencillo y poco valiente -para esas fechas- cuatrifolio, solucionándose el ochavo con sendas trompas aveneradas.

La siguiente referencia sobre su trabajo nos lo sitúa contratando colectivamente obras de cantería de menor envergadura, ya como vecino de Medina de Rioseco (Valladolid). Con los canteros Rodrigo de Viloria (vecino de Castillo en Cantabria, estante en Medina de Rioseco) y Francisco de Ortubey se había comprometido a hacer de mancomún el enlosado de la iglesia de Nuestra Señora de Medina de Rioseco; de hecho, tenían contrato de compañía para las obras medinenses desde el 2 de junio de $1546^{61}$. La obra había sido contratada con

\footnotetext{
${ }^{59}$ J. MARTí Y MONSÓ, Estudios Histórico-Artísticos relativos principalmente a Valladolid. Valladolid., 18981901, p. 530.

${ }^{60}$ M. SANGRADOR, Historia de Valladolid, 1859, p.189; J.J. MARTÍN GONZÁlEZ, "La iglesia de la Magdalena...", pp. 205-213. Sobre la intervención de Rodrigo Gil véase A. CASASECA CASASECA, Rodrigo Gil de Hontañón..., p.140.

${ }^{61}$ Además de la que motiva el pleito, en él Viloria declara que "Estas son las obras que yo rodrigo de
} 
Rodrigo de Viloria a quien el mayordomo de la obra Pedro García Magdaleno y el propio Cabañuela reclamaban en 1547 la cantidad de 18.000 maravedíes "que le piden e demandan de las quentas que entre ellos ay sobre el hedefiçio de las losas que hiçieron e pusyeron en la yglesia de nuestra señora desta dicha villa" ${ }^{62}$. El 21 de noviembre de 1547 Rodrigo de Viloria estaba preso en la cárcel real de Medina; el 15 de diciembre Juan de Nobal en nombre de Viloria, de Francisco Pérez (procurador vecino de Medina), Pedro de Castillo (vecino de Castillo) y García de Valcava (vecino de Solares ${ }^{63}$, pide que se asiente la cuenta con el mayordomo de la fábrica medinense y con los canteros Ortubey y Cabañuela. La declaración de Viloria sobre los gastos en el enlosado de la obra nos informa del trabajo de la cuadrilla de canteros cántabros y vizcaínos, compuesta por Alonso Serrano -sacador de piedra-, Domingo -desbastador-, Rodrigo del Cazo, Alonso de Anero -desbastador-, el hijo de Andrés Delgado, el mozo de Viloria, Juan Sanz de Bareyo, Francisco de la Garena, Pedro de Noja, Pedro del Castillo, Machín "vizcaíno" y sus compañeros, Pedro de Sochano, Juan de Cantera y Juan el vizcaíno.

La primera sentencia se resolvió a favor de Ortubey con la consiguiente apelación de la parte contraria, que obligó a la

\footnotetext{
biloria e francisco de hortubey tenemos hechas de conpanya son las siguientes:/primeramente en casa de salbador una escalera/mas en casa del licenciado lentes un pedaço de quebas/mas pa cristobal del aro de valdenebros dos pedaços de queba/mas en casa del mabizama (?) una entrada de escalera/mas en casa de cristobal dahumada un pedaço de quebas/mas en casa de corvalan bonetero un pedazo de queva con su escalera/mas en casa de hernando de grados dos pedaços de bobeda e una escalera/mas en casa de los palacios al patio un pedaço de queba/ mas en casa de Juan benydo una cercera ".

62 A.R.CH.V., Pl. Civiles, Alonso Rodríguez, (F), Caja 2842, exp. 2.

${ }^{63}$ Poder otorgado en Medina a 11 de diciembre de 1547.
}

declaración de testigos; así, informaron sobre el trabajo en Medina por parte de Ortubey los canteros vascos Miguel de Ydoquilez, Pedro de Olave y Juanez de Azpeitia. Destaca el interrogatorio del primero que declaró que "el dicho ortubey ny otros canteros no suelen tener ny traer libros de quentas de sus obras porque cada semana hazen sus quentas e las fenezen e se pagan unos a otros asy lo tiene de costumbre...".

Cabañuela también construyó la casa y molino del Doctor Torres en Cogeces (Valladolid). También lo sabemos por un pleito ganado por el constructor, sobre el que se emitió sentencia definitiva el 4 de julio de $1553^{64}$. A pesar del contrato firmado entre las partes, a la muerte del Doctor sus herederos (su viuda Isabel de Valdés, su hija Antonia de la Torre) no le pagaron "los gastos de mano" de la obra por lo que gracias a un mandamiento de la Chancillería de diciembre de 1549, se nombraron tasadores y se contabilizó el trabajo de Cabañuela en 388.500 maravedíes. Por parte del maestro informó Bernabé de Vega, cantero cántabro, y Pedro de Segura lo hizo por la parte contraria.

\footnotetext{
${ }^{64}$ A.R.Ch.V., Reales Ejecutorias, C.786/37. La noticia la recoge M.J. REDONDO CANTERA, "Los arquitectos y canteros del entorno de Rodrigo Gil...", p. 57.
} 


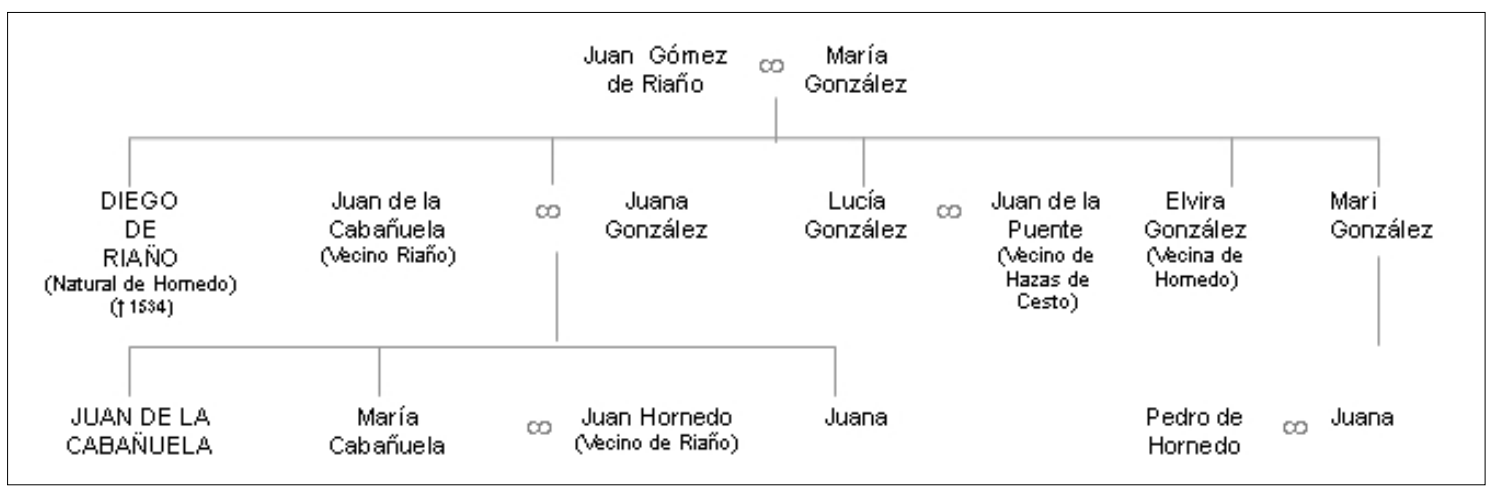

- Fig. 1. Cuadro Genealógico de Diego de Riaño. FuEnTE: A. R.CH.V., Pl. Civiles, Fernando Alonso (F), Caja 891, exp.2.

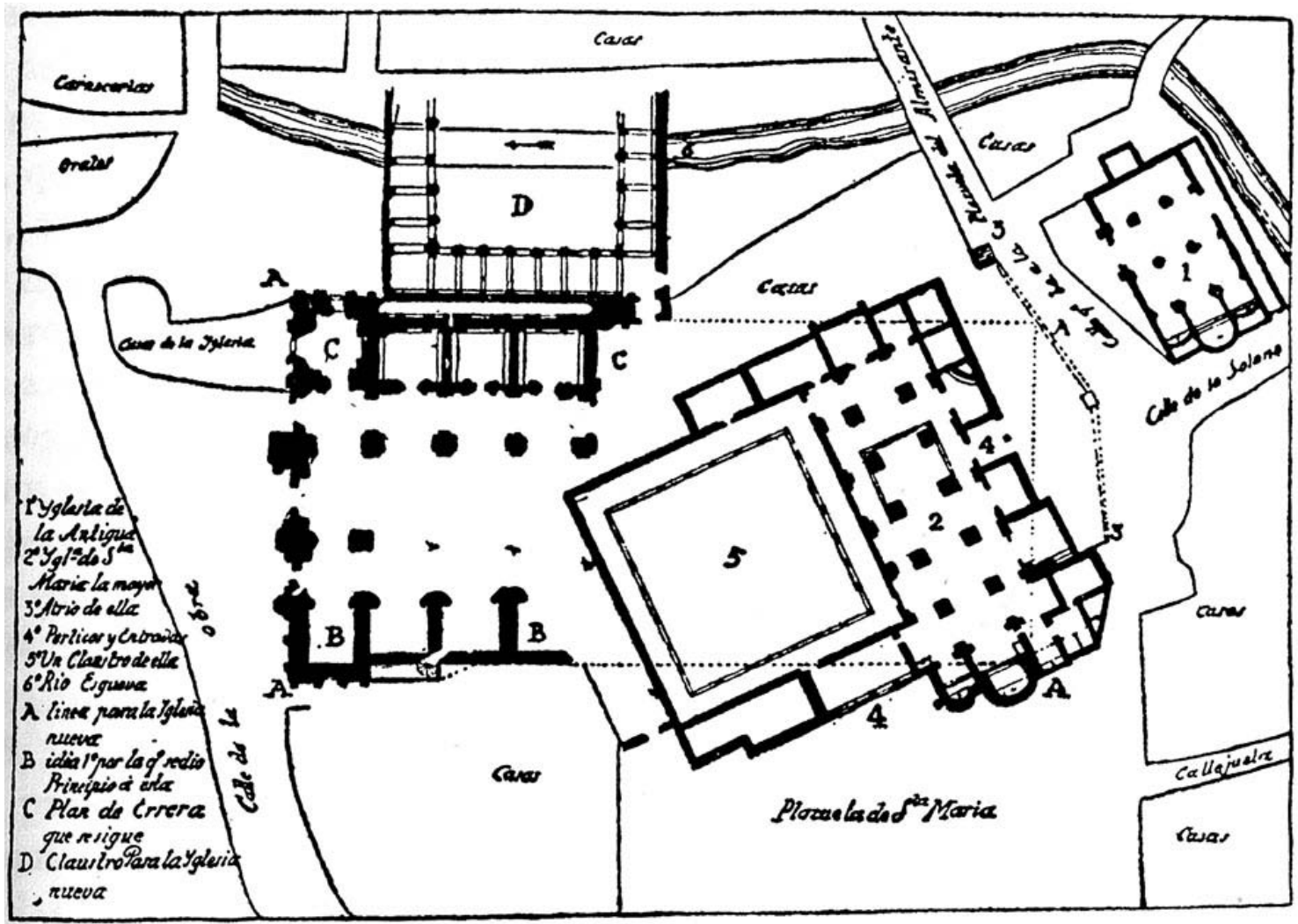

- Fig. 2. Plano de las tres iglesias mayores de Valladolid. Siglo XVII (Publicado por J. Agapito y Revilla) 


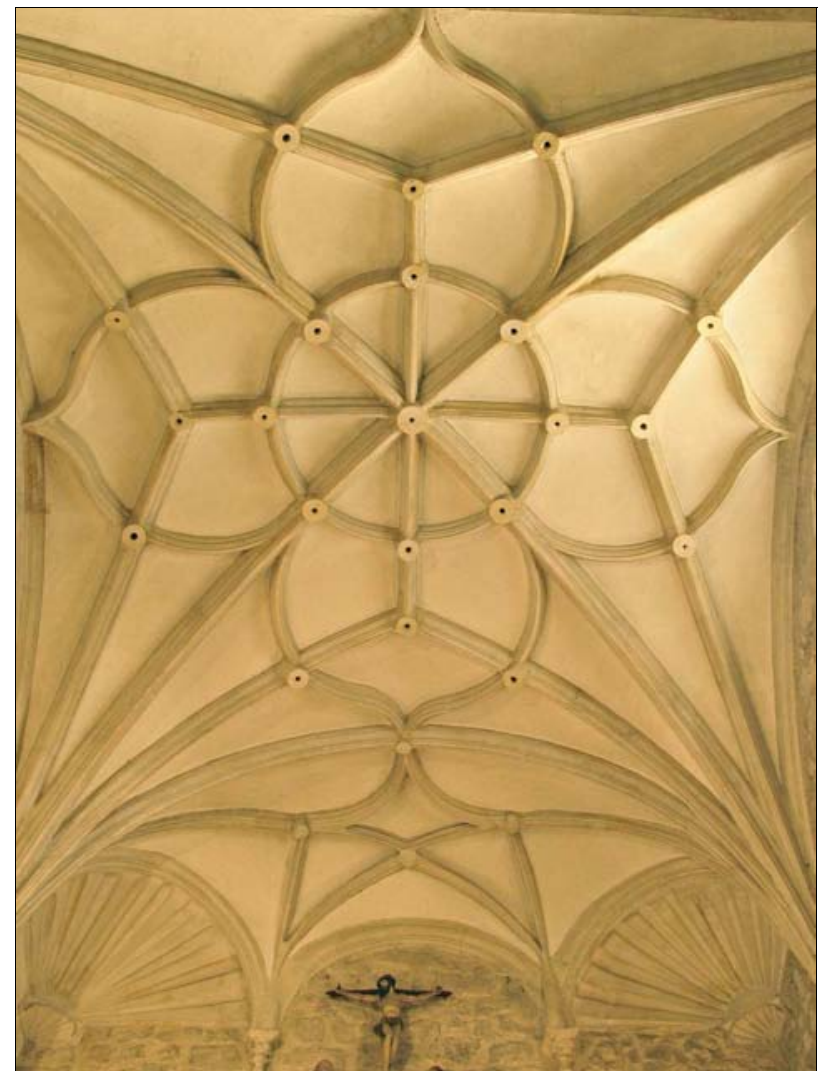

- Fig. 3. Bóveda de la Capilla del Doctor Corral en la iglesia de La Magdalena de Valladolid
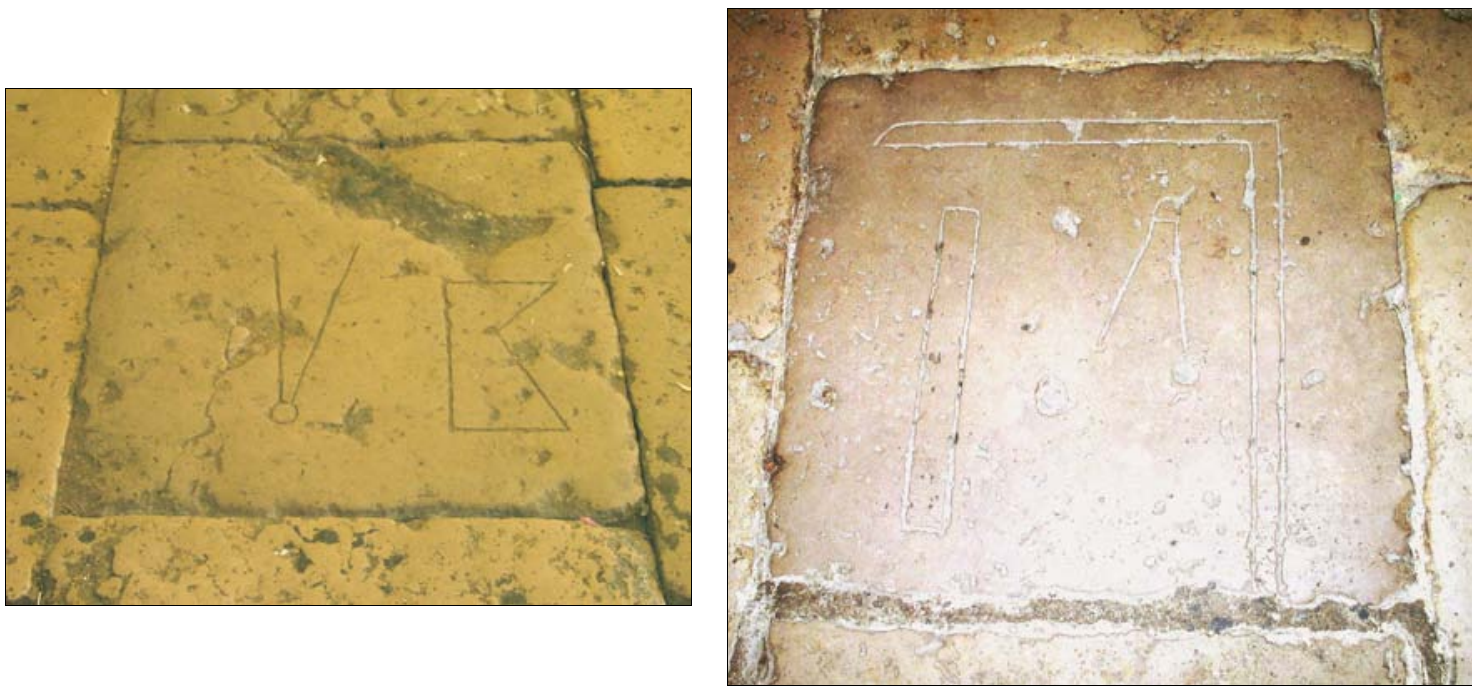

- Fig. 4/5. Detalles del enlosado de la iglesia de Santa María de Mediavilla en Medina de Rioseco (Valladolid) 